\title{
Deep-cryogenic-treatment-induced phase transformation in the Al-Zn-Mg-Cu alloy
}

\author{
Chun-mei Li $^{1,2)}$, Nan-pu Cheng ${ }^{1)}$, Zhi-qian Chen ${ }^{1)}$, Ning Guo ${ }^{1)}$, and Su-min Zeng ${ }^{1)}$ \\ 1) School of Materials Science and Engineering, Central South University, Changsha 410083, China \\ 2) School of Materials Science and Engineering, Southwest University, Chongqing 400715, China \\ (Received: 23 April 2014; revised: 12 June 2014; accepted: 18 June 2014)
}

\begin{abstract}
An aluminum alloy (Al- $\mathrm{Zn}-\mathrm{Mg}-\mathrm{Cu}$ ) subjected to deep cryogenic treatment (DCT) was systematically investigated. The results show that a DCT-induced phase transformation varies the microstructures and affects the mechanical properties of the Al alloy. Both Guinier-Preston (GP) zones and a metastable $\eta^{\prime}$ phase were observed by high-resolution transmission electron microscopy. The phenomenon of the second precipitation of the GP zones in samples subjected to DCT after being aged was observed. The viability of this phase transformation was also demonstrated by first-principles calculations.
\end{abstract}

Keywords: aluminum alloys; cryogenic treatment; phase transformation; microstructure

\section{Introduction}

Deep cryogenic treatment (DCT) is an important supplemental process after conventional heat treatment for improving the mechanical properties of ferrous metals, such as wear resistance, durability, dimensional stability, and erosion/corrosion resistance [1-2]. DCT has been reported to convert the retained austenite into martensite, enhance the volume fraction of precipitated small carbide particles, and reduce the inherent/residual stress caused by the manufacturing process [3-8].

DCT can also be used to treat nonferrous metals, such as aluminum $(\mathrm{Al})$, copper $(\mathrm{Cu})$, and magnesium $(\mathrm{Mg})$ alloys [9-22]. Strength, toughness, and hardness of $7075 \mathrm{Al}$ alloy can be enhanced with DCT. Asl et al. [20] reported that the mechanical properties of AZ91 magnesium alloy were significantly improved by DCT, which dissolved tiny laminar $\beta$ particles into the microstructure and facilitated the penetration of the coarse divorced eutectic $\beta$ phase into the matrix. Moreover, Ma et al. [22] noted that the martensitic phase transformation of $\mathrm{B} 2 \mathrm{CuZr}$ phase to $\mathrm{B} 19^{\prime} \mathrm{CuZr}$ phase induced by $\mathrm{DCT}$ in a $\mathrm{Cu}-\mathrm{Zr}-\mathrm{Al}$ bulk metallic glass composite increased its microhardness and ultimate compression fracture strength. All these aforementioned results indicate that atom diffusion and phase transformation can still occur during DCT, even though the temperature used in the process is very low.

In addition to experimental studies, the first-principles calculation, which is one of the most important theoretical methods, has been widely used to investigate phase transformations in nonferrous metals [23-27], such as the transformation of the $\theta$ phase in $\mathrm{Mg}-\mathrm{Li}-\mathrm{Al}$ alloys [23], the transformation of typical precipitates $\left(\mathrm{Mg}_{2} \mathrm{Si}, \mathrm{Mg}_{2} \mathrm{Ge}\right.$, $\mathrm{Mg}_{2} \mathrm{Sn}$, and $\mathrm{Mg}_{3} \mathrm{Zn}_{3} \mathrm{Y}_{2}$ ) in creep-resistant magnesium alloys [24], and the transformation effects of B impurities in NiAl intermetallics [26]. Zhang et al. [27] successfully investigated the phase transformations induced by an electric field by calculating the Gibbs free energy of atom clusters in an $\mathrm{Al}-\mathrm{Cu}-\mathrm{Li}$ alloy. However, the transformation of precipitates during DCT in Al alloys has not been adequately investigated with either experimental methods or theoretical approaches.

In the current study, the DCT-induced phase transformation and the mechanical properties of the $\mathrm{Al}-\mathrm{Zn}-\mathrm{Mg}-\mathrm{Cu}$ alloy were studied by experimental tests combined with

Corresponding author: Chun-mei Li E-mail: 1cm1998@swu.edu.cn 
first-principles calculations.

\section{Experimental}

\subsection{Experimental methods}

An Al alloy (Al-Zn0.078-Mg0.018-Cu0.015) was prepared by semi-continuous casting. The as-received samples were step-homogenized at $430^{\circ} \mathrm{C}$ for $18 \mathrm{~h}$ and then at $467^{\circ} \mathrm{C}$ for $4 \mathrm{~h}$. Traditionally, homogenized materials are subjected to extrusion, solution with quenching, and aging prior to their final application. To obtain the optimal DCT soaking time, the samples were subjected to a single deep cryogenic treatment in liquid nitrogen at $-197^{\circ} \mathrm{C}$ after being subjected to extrusion, quenching, and aging treatments. Vickers hardness measurements were carried out on samples at each state. A load of $49 \mathrm{~N}$ was applied for $30 \mathrm{~s}$ using a diamond Vickers indenter. The experimental results are shown in Fig. 1 , which illustrates that the DCT time strongly affects the hardness of the samples. The hardness does not increase linearly with the increase in DCT time and decreases when the DCT time is prolonged. As shown in Fig. 1, the optimum duration of DCT is approximately $36 \mathrm{~h}$.

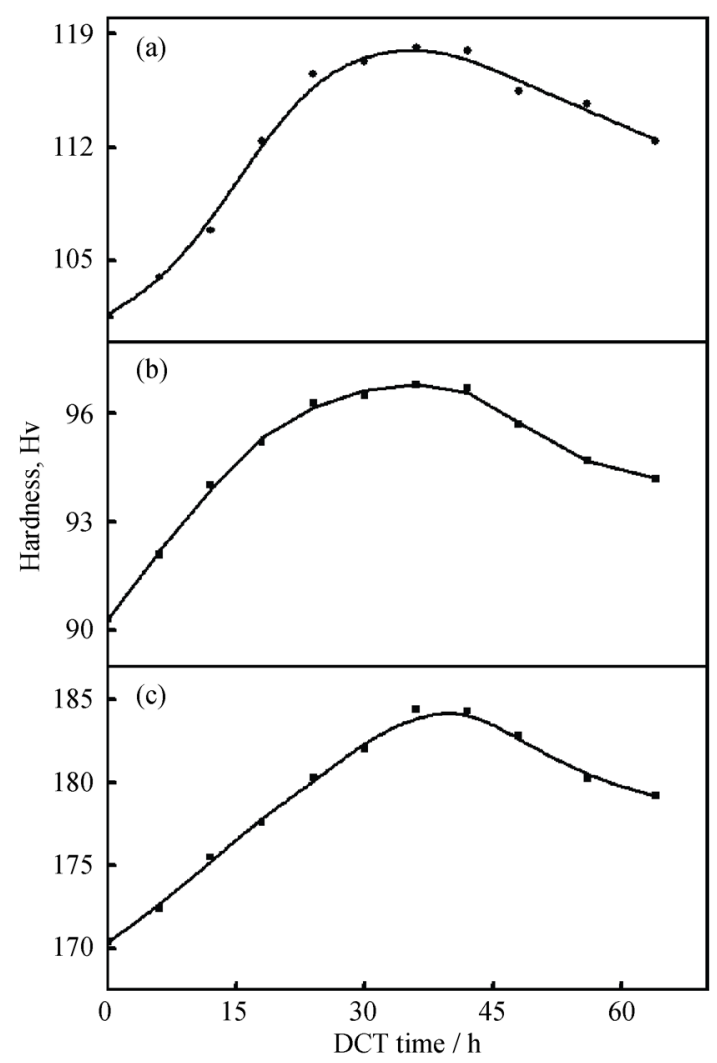

Fig. 1. Vickers hardness of the samples as a function of the DCT time: (a) extruded samples; (b) quenched samples; (c) aged samples.
In the following study, the DCT process was used one or multiple times in addition to the traditional solution and aging treatments at different stages. Ten schemes were designed for the DCT process (Table 1).

Table 1. Experimental schemes for the extruded samples

\begin{tabular}{|c|c|c|c|c|c|}
\hline $\begin{array}{l}\text { Sample No. } \\
\text { (as extruded) }\end{array}$ & $\begin{array}{c}\text { DCT fo } \\
36 \mathrm{~h}\end{array}$ & $\begin{array}{c}\text { Solution with } \\
\text { quenching }\end{array}$ & $\begin{array}{l}\mathrm{CT} \text { for } \\
36 \mathrm{~h}\end{array}$ & Aging & DCT \\
\hline 1 & & $\diamond$ & & $\bullet$ & \\
\hline 2 & $\diamond$ & $\diamond$ & & $\diamond$ & \\
\hline 3 & & $\diamond$ & $\diamond$ & 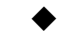 & \\
\hline 4 & & $\diamond$ & & $\diamond$ & for $18 \mathrm{~h}$ \\
\hline 5 & & $\diamond$ & & $>$ & for $24 \mathrm{~h}$ \\
\hline 6 & & $\diamond$ & & $\diamond$ & for $36 \mathrm{~h}$ \\
\hline 7 & & $\diamond$ & & $\diamond$ & for $48 \mathrm{~h}$ \\
\hline 8 & $\bullet$ & $\diamond$ & & $\diamond$ & for $36 \mathrm{~h}$ \\
\hline 9 & & $\diamond$ & $\diamond$ & $\diamond$ & for $36 \mathrm{~h}$ \\
\hline 10 & $\diamond$ & $\diamond$ & $\diamond$ & $\diamond$ & for $36 \mathrm{~h}$ \\
\hline
\end{tabular}

The tensile mechanical properties were tested at room temperature on a GALDABINI SUN5 electronic tension machine. The Vickers hardness was determined using a HXP-1000TM digital hardness tester. X-ray diffraction (XRD) was conducted using a RIGAKU 2500PC X-ray diffractometer. The microstructures were examined using a Hitachi S-3400N scanning electron microscope (SEM) and a Tecnai $\mathrm{G}^{2} 20$ high-resolution transmission electron microscope (HRTEM). Specimens for transmission electron microscopy (TEM) were prepared by jet polishing with a MTP-1A twin-jet electropolisher at $-40^{\circ} \mathrm{C}$ (in a solution of 10vol\% nitric acid and 90vol\% methanol).

\subsection{Computational methods}

In general, the thermodynamic properties and phase stability in experimental study are determined by the chemical potential - specifically, the molar Gibbs energy $G$, which can be calculated by

$G=H-T S$

where $H$ is the enthalpy, $S$ the entropy, and $T$ the temperature. $H$ is a function of temperature and is calculated using the results of vibrational analysis or Hessian evaluation as follows [28]:

$H(T)=E_{\mathrm{vib}}(T)+E_{\mathrm{rot}}(T)+E_{\text {trans }}(T)+R T$

where $E_{\mathrm{vib}}, E_{\mathrm{rot}}$, and $E_{\text {trans }}$ represent the vibrational, rotational, and translational contributions, respectively, and $R$ is the ideal gas constant. The former three contributions are given by 


$$
\begin{aligned}
& E_{\text {vib }}=\frac{R}{k} \frac{1}{2} \sum_{i} h v_{i}+\frac{R}{k} \sum_{i} \frac{h v_{i} \exp \left(-h v_{i} / k T\right)}{\left[1-\exp \left(-h v_{i} / k T\right)\right]}, \text { for } \\
& Q_{\text {vib }}=\sum_{i} \frac{1}{\left[1-\exp \left(-h v_{i} / k T\right)\right]} \\
& E_{\text {rot }}(\text { linear })=R T \\
& E_{\text {rot }}(\text { nonlinear })=3 R T / 2 \\
& E_{\text {trans }}=3 R T / 2
\end{aligned}
$$

where $k$ is the Boltzmann constant, $h$ is the Planck's constant, $Q_{\text {vib }}$ is the partition function of $E_{\text {vib }}$, and $v_{i}$ represents the individual vibrational frequencies ( $E_{\text {rot }}$ (linear) and $E_{\text {rot }}$ (nonlinear) are used for linear and nonlinear systems, respectively).

The contributions to the entropy $S$ in Eq. (1) are given by $S(T)=S_{\text {vib }}(T)+S_{\text {rot }}(T)+S_{\text {trans }}(T)$

where $S_{\text {vib }}, S_{\text {rot }}$, and $S_{\text {trans }}$ represent the vibrational, rotational, and translational contributions, respectively.

$$
\begin{aligned}
& S_{\text {vib }}=R \sum_{i} \frac{h v_{i} / k T \exp \left(-h v_{i} / k T\right)}{1-\exp \left(-h v_{i} / k T\right)}+ \\
& R \sum_{i} \ln \left[1-\exp \left(-h v_{i} / k T\right)\right] \\
& S_{\text {rot }} \text { (linear) }=R \ln \left(\frac{8 \pi^{2} I k T}{\sigma h^{2}}\right)+R \\
& S_{\text {rot }} \text { (nonlinear) }= \\
& \quad \frac{R}{2} \ln \left[\frac{\pi}{\sqrt{\sigma}} \frac{8 \pi^{2} c l_{\mathrm{A}}}{h} \frac{8 \pi^{2} c l_{\mathrm{B}}}{h} \frac{8 \pi^{2} c l_{\mathrm{C}}}{h}\left(\frac{k T}{h c}\right)^{3}\right]+\frac{3}{2} R \\
& S_{\text {trans }}=\frac{5}{2} R \ln T+\frac{3}{2} R \ln \omega-R \ln p-2.31482
\end{aligned}
$$

where $\sigma$ is the symmetry number, $w$ is the molecular weight, $l$ is the directional cosine of the system to the axis, and the other quantities are as previously described. $S_{\text {rot }}$ (linear) and

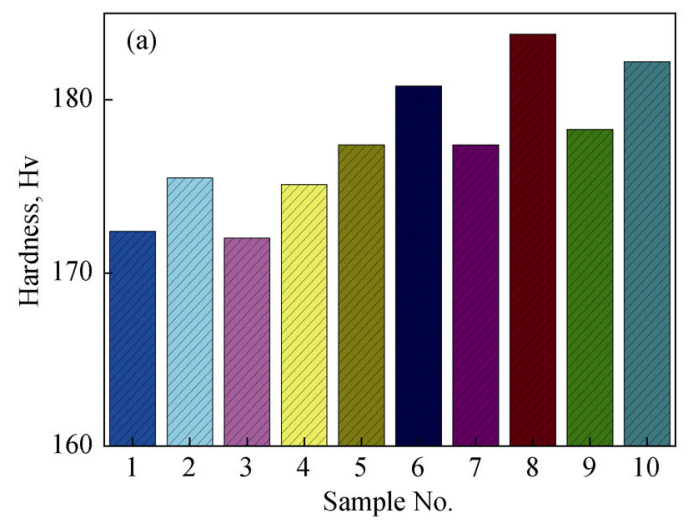

$S_{\text {rot }}$ (nonlinear) are used for linear and nonlinear systems, respectively.

First-principles calculations were performed using the plane-wave pseudo-potentials with the generalized gradient approximation refined by Perdew, Burke, and Ernzerhof. The macrocanonical ensemble NVT was chosen for the calculations of the Guinier-Preston (GP) zone and the metastable $\eta^{\prime}$ phase of the aged $\mathrm{Al}-\mathrm{Zn}-\mathrm{Mg}-\mathrm{Cu}$ alloy.

\section{Results and discussion}

\subsection{Mechanical properties}

Fig. 2 presents the mechanical properties of the samples listed in Table 1; the results from three-staged experiments are summarized. In the first stage, samples 1, 2, 3, and 5 were designed to elucidate the effect of a single 36-h DCT performed on samples in the as-extruded, as-quenched, or as-aged state. The results show that the single DCT performed on samples in the as-aged state most strongly influenced the properties of the observed Al alloy. Accordingly, in the second stage, we further investigated the variable of DCT processing time following aging using samples 4-7. We observed that the mechanical properties improved with the increase in DCT time before reaching a peak value at 36 $\mathrm{h}$, and then decreased. On the basis of the experimental results for samples $1-7$, we performed combinatorial DCTs on samples $8-10$ in the third stage. The results indicated that sample 8 , prepared using the scheme of extrusion + DCT $(36 \mathrm{~h})+$ solution + quenching + aging + DCT (36 h), exhibited the highest hardness and strength among the prepared samples.

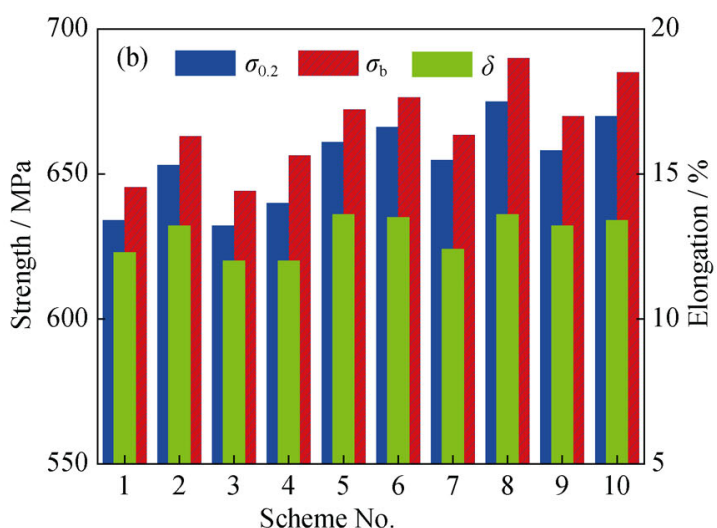

Fig. 2. Mechanical properties of the samples: (a) Vickers hardness; (b) tensile properties.

As a whole, together with Fig. 1, Fig. 2(a) indicates that with the exception of sample 4 , the hardness of the samples subjected to DCT while in their as-extruded or/and as-aged states can be increased to various extents and that the effects 
of multiple DCTs in the same scheme are not simply additive. At the same time, the effect of DCT applied to samples in the as-quenched state is not retained after the subsequent heat treatment. The variation of the yield and tensile strengths shown in Fig. 2(b) is similar to that of the Vickers hardness in Fig. 2(a), and elongation of the samples is relatively less obviously changed by DCT compared with strength. Moreover, comparisons of sample 3 with 1 , sample 9 with 6 , and sample 10 with 8 reveal that DCT only slightly influences the properties of the $\mathrm{Al}$ alloy in all of the schemes as long as it is performed after the samples have been quenched. This phenomenon is mainly attributable to the application of DCT prior to the traditional high-temperature aging process serving as a pre-aging process of the alloy, inducing nucleus formation of the GP zone. However, this effect disappears after subsequent aging at high temperatures. The detailed reasons for the variation of the mechanical properties among samples in different states after the samples have been subjected to a DCT will be further discussed in the following sections.

\subsection{Microstructures}

Fig. 3(a) shows an SEM image of sample 1, which was not subjected to DCT, whereas Fig. 3(b) shows an image of sample 2, which was subjected to DCT. A comparison of Figs. 3(b) and 3(a) reveals that the DCT process facilitates to grain refinement, which results in an increase of hardness, as shown in Fig. 2. Fig. 3(c) shows a TEM image of sample 1, whereas Figs. 3(d)-3(e) show the images of sample 2. The images indicate that $\mathrm{Al}$ matrix grains are refined by the subgrain boundaries generated by dislocation climbing and sliding, which are driven by the deformation energy stored during extrusion. The formation of subgrains consumes the deformation energy, decreases the driving energy for grain growth during the subsequent solution treatment, and diminishes the grain growth rate in the Al matrix.

Figs. 3(f)-3(h) show the precipitate distribution in the $\mathrm{Al}$ matrix of sample 1, whereas Figs. $3(\mathrm{k})-3(\mathrm{~m})$ display the precipitate distribution in sample 6 . The precipitates in these two different states both exhibit uniformly dispersed distributions in grains as well as discontinuous distribution along grain boundaries, accompanied by a $30-40-\mathrm{nm}$ wide precipitate-free zone. These results indicate that DCT performed after aging maintains this favorable microstructural morphology along the grain boundaries of the aged $\mathrm{Al}$ alloy. However, as shown in Figs. 3(h) and 3(m), the lattice structures of the precipitates in the grains of these two states are essentially different; we therefore further investigated these lattice structures using SAED and HRTEM.
Figs. 3(i)-3(j) and Figs. 3(n)-3(o) present the SAED patterns along the $<001>$ and $<111>$ zone axes of sample 1 (not subjected to DCT) and sample 6 (subjected to DCT) (Table 1).

The diffraction spots from the $\mathrm{Al}$ matrix are indexed in Figs. 3(i)-3(j) and Figs. 3(n)-3(o). The pattern of the aged sample 1 in Fig. 3(i), according to Fig. 3(p) [29], shows the strong sets of spots associated with the metastable hardening phase $\eta^{\prime}$; the spots appear at $1 / 3$ and $2 / 3$ of the $<220>$ matrix reflections. The weak spots mainly located to the left and right of $2 / 3$ of the $<220>$ matrix reflections describe the stable phase $\eta$. No clear spots associated with the GP zone appear in the [001] patterns in Figs. 3(i) and 3(n). Furthermore, no GP spots are observed in Fig. 3(j). Together with the results in Fig. 3(i), these results indicate that no GP zone existed in sample 1. However, in Fig. 3(o), the SAED pattern of sample 6 (subjected to DCT) after aging shows clear spots related to the GPII zone, and sets of three spots corresponding to three different $\langle 110\rangle_{\mathrm{Al}}$ directions locate around the $<422>/ 3_{\mathrm{Al}}$ position. The spots along $\langle 422\rangle_{\mathrm{Al}}$ are the strongest, and the other two sets of spots in the group are the results of double scattering by a 220-type matrix reflection [30]. Note that the [001] Al matrix direction is not suitable for the observation of GPII zones, whereas the [111] and [112] directions of $\mathrm{Al}$ matrix are more reasonable for the detection of GPII; this difference is the reason why GPII spots appear in Fig. 3(o) but not in Fig. 3(n).

On the basis of the aforementioned analysis, the use of DCT after aging results in an increase in the density of the GPII zone, which can be attributed to two factors. First, it can be attributed to the second precipitation of a GPII zone during DCT. Second, the reverse phase transformation from the $\eta^{\prime}$ phase to the GPII zone during DCT after aging may also result in an increase in the quantity of GPII zones. We further analyzed this second possibility through a combination of HRTEM images and first-principles calculations.

The HRTEM observations of GPII zones and the $\eta$ ' phase of the $\mathrm{Al}$ alloy were usually performed along the $\langle 111\rangle_{\mathrm{Al}}$ and $\langle 112\rangle_{\text {Al }}$ zone axes. Figs. 4(a) -4 (c) show the HRTEM images collected in the $\langle 112\rangle_{\mathrm{Al}}$ projections of sample 1 , which was subjected to a traditional heat treatment. According to Fig. 4(d) [29], the fast Fourier transformation (FFT) images of the precipitates indicate that they are mainly the $\eta^{\prime}$ phase with a small quantity of stable $\eta$ phase and that most of the $\eta^{\prime}$ precipitates are $3-5 \mathrm{~nm}$ in length along the $c$ axis and $5-7 \mathrm{~nm}$ in diameter parallel to the plane of the $a-b$ axes. The enlarged image of the precipitate outlined in Fig. 4(a) is illustrated in Fig. 4(b), where periodic ring chains separated by wave-like lines are observed. These observations are 


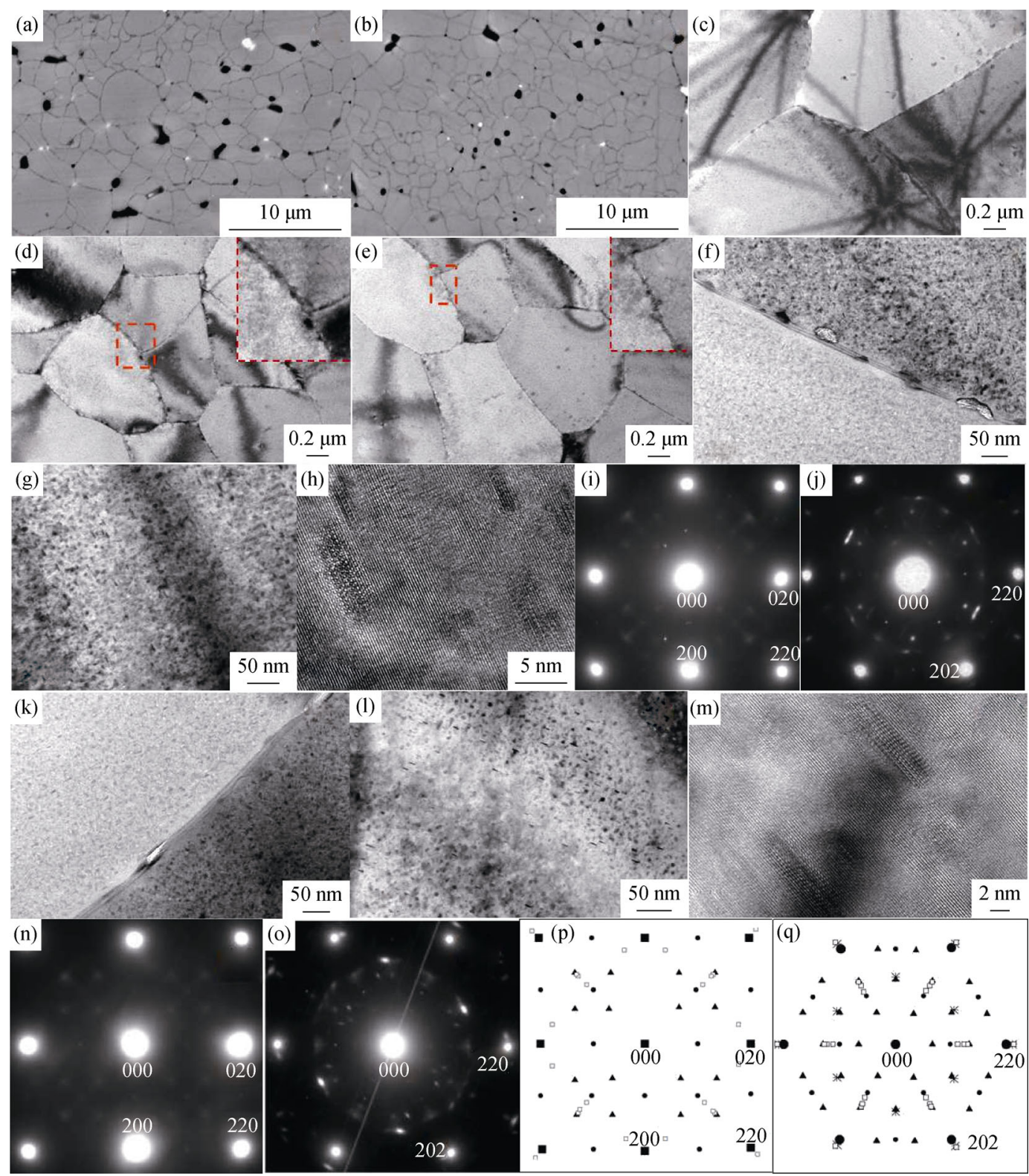

Fig. 3. SEM and TEM images and selected area electron diffraction (SAED) patterns of different samples subjected or not subjected to a DCT: (a) SEM image of sample 1; (b) SEM image of sample 2; (c) TEM image of sample 1; (d,e) TEM images of sample 2; (f,g,h) TEM images of sample 1; (i,j) SAED patterns of sample 1; (k,l,m) TEM images of sample 6; (n,o) SAED patterns of sample 6; $(p, q)$ schematic representation of the [001] and [111] patterns (small solid circles: $\mathrm{Al}_{3} \mathrm{Zr}$; small open squares: $\eta$; solid triangles: $\eta$ '; crosses: GPII with several orientation variants).

consistent with the lattice structure of the $\eta^{\prime}$ phase along its six-fold axis. A red rectangular box corresponding to the (11) 0 ) plane of the unit cell of the $\eta^{\prime}$ phase is drawn in Fig. 4 (b). The length of the unit cell along the $\langle 111\rangle_{\mathrm{Al}}$ projection is $1.4 \mathrm{~nm}$, and its width along the $\langle 220\rangle_{\mathrm{Al}}$ projection is 0.86 $\mathrm{nm}$; these results are consistent with the lattice parameters, $c$ $=1.402 \mathrm{~nm}$ and $1.732 a=0.86 \mathrm{~nm}(a=0.496 \mathrm{~nm})$, of the $\eta^{\prime}$ phase. The FFT image in Fig. 4(c) further confirms that the precipitate is $\eta^{\prime}$-phase.
Figs. 4(e)-4(i) show the HRTEM images of sample 6 (subjected to DCT after aging), which were also taken with the incident electron beam parallel to the $<112>$ zone axis of the $\mathrm{Al}$ matrix. The images indicate that the precipitates in Fig. 4(e) include numerous GPII zones and transition structures between the GPII zones and $\eta^{\prime}$ phase. Enlarged images of the transition stage and the GPII zone are shown in Figs. 4(g) and 4(i), and the corresponding FFT images are shown in Figs. 4(f) and 4(h), respectively. The marked unit cell in 
Fig. $4(\mathrm{~g})$ reveals a main feature of the transition structure from ring chains to wave-like lines. The lattice distribution of the transition structure is similar to that of GPII, not to that of the $\eta^{\prime}$ phase; conversely, its lattice parameter is simi- lar to that of $\eta^{\prime}$ phase but not similar to that of GPII. Fig. 4(i) shows the enlarged image of the GPII zone showing only wave-like lines, which can be distinguished from the diffuse diffraction spots of GPII near the $<311>_{\mathrm{Al}} / 2$ axis in Fig. 4(h).

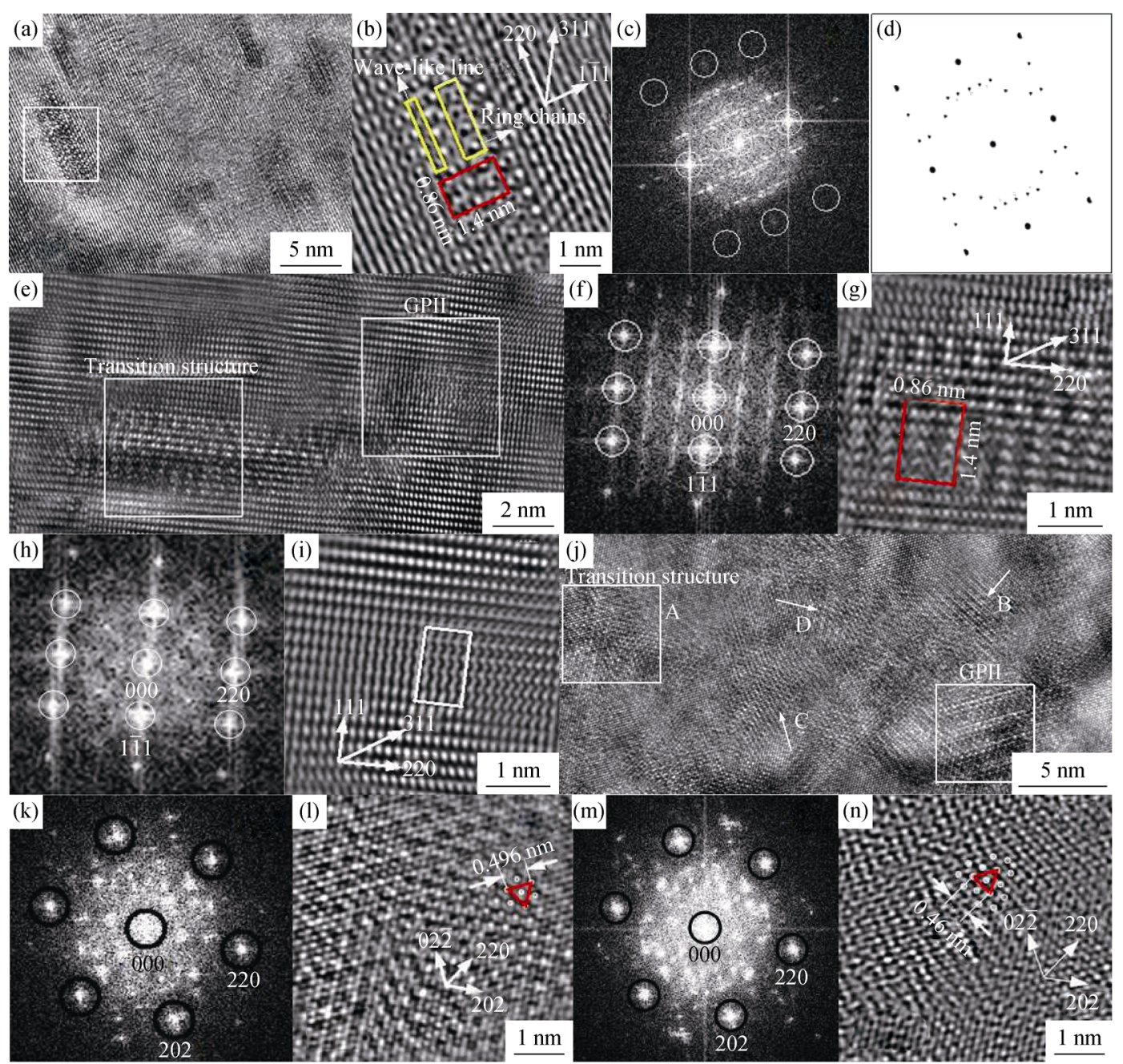

Fig. 4. HRTEM images along the $[112]_{\mathrm{Al}}$ and $[111]_{\mathrm{Al}}$ projections of the samples: (a) full image of sample 1; (b) enlarged image of one precipitate in sample 1; (c) FFT pattern of the precipitate in image (b); (d) schematic of the [112] patterns (small open squares: $\eta$; filled triangles: $\eta^{\prime}$ with several orientation variants); (e) full image along the $[112]_{\mathrm{Al}}$ projection of sample 6 ; (f) FFT pattern of the transition structure in image (e); (g) enlarged image of the transition structure in image (e); (h) FFT pattern of the GPII zone in image (e); (i) enlarged image of the GPII zone in image (e); (j) full image along the $[111]_{\mathrm{Al}}$ projection of sample 6; (k) FFT pattern of the transition structure in image (j); (l) enlarged image of the transition structure in image (j); (m) FFT pattern of the GPII zone in image (j); (n) enlarged image of the GPII zone in image (j).

To obtain more information about the precipitates of the sample subjected to DCT after aging, we collected a HRTEM image in the $\langle 111\rangle_{\text {Al }}$ projection, as shown in Fig. 4(j). The FFT and enlarged images of precipitate A in Fig. 4(j) are shown in Figs. 4(k) and 4(l), respectively. Fig. 4(k), in conjunction with Fig. 3(q), indicates that the precipitate exhibits a transition structure between the $\eta^{\prime}$ phase and GPII structures; i.e., it has the same lattice parameter as the $\eta^{\prime}$ phase, but is nearly coherent with the Al matrix. GPII zones also frequently appear in the matrix, as determined from FFT images. As is well known, the GPII zones are planar $\{111\} \mathrm{Zn}$ sheets with a slight lattice-position offset relative to the Al matrix [30]. In Fig. 4(n), the spacing between the centers of two adjacent hexagons outlined with a triangle is $0.46 \mathrm{~nm}$, which is slightly less than the lattice parameter ( $a$ $=0.496 \mathrm{~nm}[31-32])$ of the $\eta^{\prime}$ phase but is equal to the lattice parameter of the GPII zone [30] and is also consistent with the strong radial spots near the $<422>/ 3$ positions in 
Figs. 4(m), 4(h), and 3(q). On the basis of the aforementioned analysis, precipitate $\mathrm{A}$ is the transition structure with its $c$ axis along the electron incident direction. Precipitates B, C, and D in Fig. 4(j) are actually also the transition structure or GPII zones with different profiles formed by different transition structures or GPII sheets in others intersecting with the observed $\{111\}_{\text {Al }}$ plane.

A comparison of Figs. 4(e)-4(n) with Figs. 4(a)-4(c) reveals that numerous transition structures and GPII zones appear in the Al matrix subjected to DCT after aging. Furthermore, we deduced that DCT after aging can induce an increase in the quantity of GPII zones. We systematically investigated, from the viewpoint of atom lattice distribution and phase-transformation thermodynamics, whether this increase results from the reverse phase transformation from the $\eta^{\prime}$ phase to a GP zone or from the second precipitation of GP zones.

\subsection{First-principles calculations}

The GPII zones are planar (111) sheets with a high $\mathrm{Zn}$ content in an Al matrix, and the (0001) and (11̄20) planes of the $\eta^{\prime}$ phase are always parallel to the (111) and (110) planes, respectively, of the Al matrix. Therefore, the (111)

plane of the Al matrix (Fig. 5(a)) is suitable for analysis of the phase transformation between the GPII zone and $\eta^{\prime}$ phase. Fig. 5(b) shows the structural projection of the $\mathrm{Al}$ matrix with three layers along the $<111>$ zone axis. The replacement of $\mathrm{Al}$ atoms with $\mathrm{Zn}$ atoms results in the formation of a GPII zone. The adjacent atoms in the upper and under layers around one $\mathrm{Zn}$ atom in the middle layer will form the erected and inverted triangular bonds (the diagram in Fig. 5(b)). Since $\mathrm{Zn}$ has a smaller radius than $\mathrm{Al}$, the spacing between the rows of atoms is approximately $6 \%$ to $8 \%$ less than that in the Al matrix; this diminished spacing results in the diffraction spots near the $\{422\} / 3$ of the $\mathrm{Al}$ matrix in the $\{111\}$ reciprocal plane (Fig. $4(\mathrm{~m})$ ). Given that $\mathrm{Zn}$ atoms at the special positions in the middle layer of the GP zone are replaced with $\mathrm{Mg}$ atoms (Fig. 5(c)), the unit of the transition structure between the GPII zone and the $\eta^{\prime}$ phase is constructed. Simultaneously, since the $\mathrm{Mg}$ atom has a larger radius than $\mathrm{Zn}$ and $\mathrm{Al}$ atoms, the contraction of the interatomic distance in the upper and under layers in the GPII zone is offset by the replaced $\mathrm{Mg}$ atoms in the middle layer. Thus, the lattice parameter of the $\eta^{\prime}$ phase becomes larger than that of the GPII, which results in the diffraction spots at $\{422\} / 3$ and $\{220\} / 3$ of the Al matrix in the
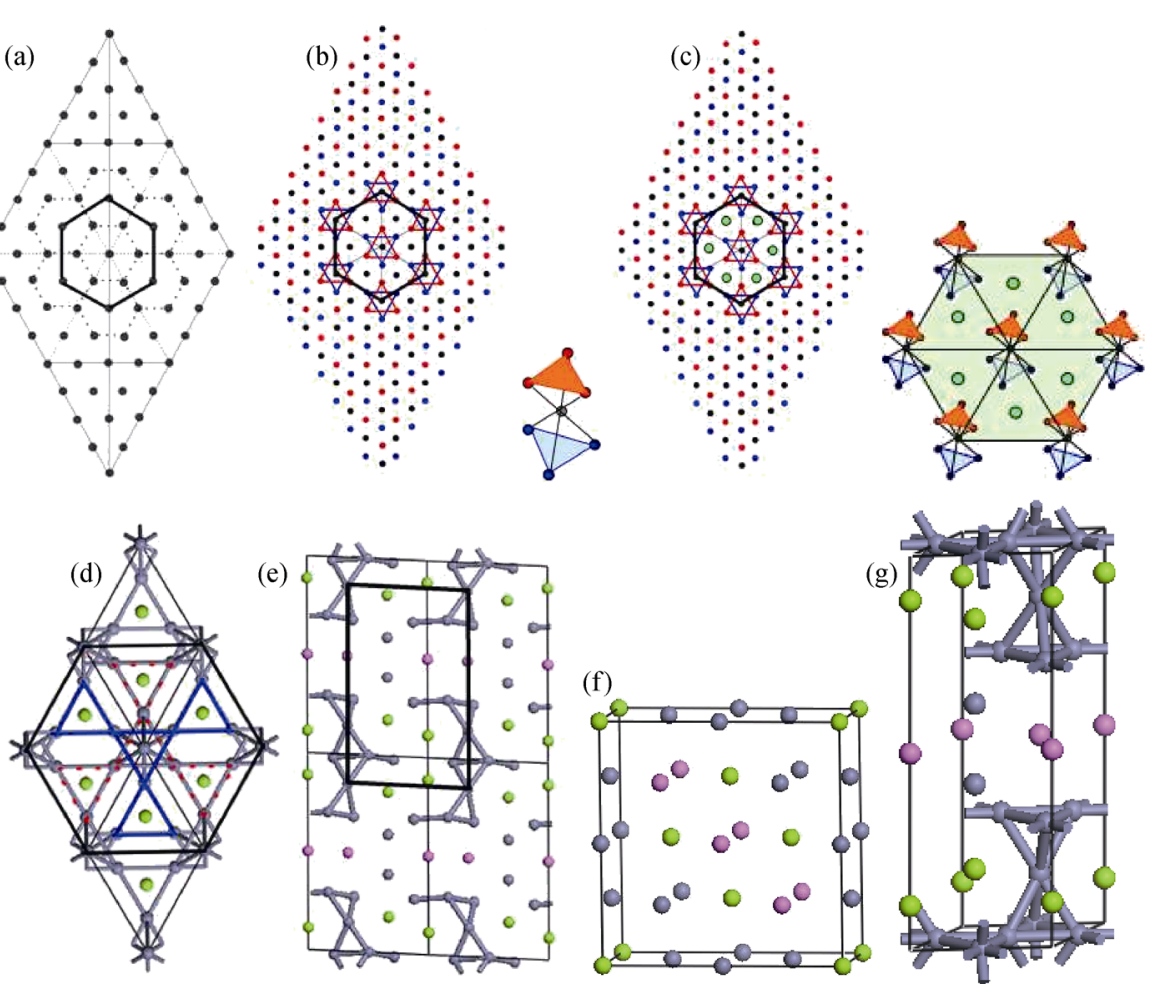

atoms in the upper layer; 1 atoms in the middle layer;

atoms in the under layer;

$\mathrm{Mg}$ atoms in the middle layer; $\mathrm{Al} ; \mathrm{Og}$;

- Zn.

Fig. 5. Schematics of the structural projection along the $[111]_{\mathrm{Al}}$ and the crystal structures of the calculated unit cells: (a) (111) plane of $\mathrm{Al}$; (b) three (111) layers of $\mathrm{Al}$; (c) transition structure between the GPII and $\eta^{\prime}$ phase with three layers; (d) $\eta^{\prime}$ phase along the [0001] zone axis; (e) (11 $\overline{2} 0)$ plane of the $\eta^{\prime}$ phase; (f) GPII zone; (g) $\eta^{\prime}$ phase. 
reciprocal planes (Figs. 3(j), 3(q), and 4(c)). The representative structural projection of the $\eta^{\prime}$ phase along the $<0001>$ zone axis can be constructed as shown in Fig. 5(d). In addition, the $(11 \overline{2} 0)$ plane of $\eta^{\prime}$ phase is shown in Fig. 5(e), where every two repeating units consisting of $\mathrm{Zn}$ atoms and interstitial $\mathrm{Mg}$ atoms are separated by one layer of $\mathrm{Al}$ atoms. The layers consisting of $\mathrm{Zn}$ and $\mathrm{Mg}$ atoms in Fig. 5(e) present as ring chains, and the separating layer of $\mathrm{Al}$ atoms presents as wave-like lines, which is consistent with the experimental results of $\eta^{\prime}$ phase in Fig. 4(b). In general, the GPII zones of 1-2 nm thick and 3-4 nm wide always appear as thin objects parallel to the (111) planes (Fig. 4(i)) [30], and most of the $\eta^{\prime}$ phases are observed within a thickness of $3-5 \mathrm{~nm}$ along the $c$ axis and within a width of 5-7 nm in the (0001) plane of the $a-b$ axes (Fig. 4(b)).

According to the current study and the other previous studies [30-31,33-34], the crystal structures are built as shown in Figs. 5(f)-5(g), and the unit-cell parameters of the precipitates (the GPII zone and metastable $\eta$ ' phase) are shown in Table 2. The GPII zone is a Zn-rich layer in the $\{111\}$ planes of the $\mathrm{Al}$ matrix and expands along the $<110>$ direction of the $\mathrm{Al}$ lattice. The metastable phase $\eta^{\prime}$, with lattice parameters of $a=0.496 \mathrm{~nm}=[211]_{\mathrm{Al}} / 2$ and $c=1.40 \mathrm{~nm}=2[111]_{\mathrm{Al}}$, is semi-coherent with the $\mathrm{Al}$ matrix, as previously discussed.

Table 2. Lattice parameters of the calculated precipitates

\begin{tabular}{cccccccccc}
\hline Phases & Crystal system & Space group & $a / \mathrm{nm}$ & $b / \mathrm{nm}$ & $c / \mathrm{nm}$ & $\alpha /\left(^{\circ}\right)$ & $\beta /\left(\left(^{\circ}\right)\right.$ & $\gamma /\left(^{\circ}\right)$ \\
\hline GPII & Tetragonal & $I 4 / m c m$ & 0.405 & 0.81 & 0.81 & 90 & 90 & 90 \\
$\eta^{\prime}$ & Hexagonal & $P \overline{6} m 2$ & 0.496 & 0.496 & 1.402 & 90 & 90 & 120 \\
$\eta^{\prime}$ (experimental data) & Hexagonal & $P \overline{6} m 2$ & $0.496[34]$ & $0.496[34]$ & $1.40[34]$ & 90 & 90 & 120 \\
\hline
\end{tabular}

The $\mathrm{Al}-\mathrm{Zn}-\mathrm{Mg}-\mathrm{Cu}$-series alloys are typical precipitation strengthening Al alloys. At high temperatures, a generally accepted precipitation pattern is supersaturated solid solution-GP (GPI and GPII)-metastable phase $\eta^{\prime}$-stable phase $\eta$, and each phase transformation step is an exothermic process to obtain a lower system energy at a certain temperature [29-30,33,35-37].

On the basis of our aforementioned experimental observations and theoretical analyses, the transformation process is reversible with respect to the crystal structures of the phases. However, whether the appearance of GP zones arises from the reverse phase transformation of $\eta^{\prime}$ phase to GPII or from the second precipitation of GP zones is determined by the thermodynamic conditions according to the lowest energy principle.

Fig. 6(a) shows the theoretical results of the Gibbs free energy of the GPII zone and metastable $\eta^{\prime}$ phase calculated on the basis of the first-principles calculation and the statistical thermodynamics theory. All of the free energies of the GPII zone and metastable $\eta^{\prime}$ phase decrease with the increase in temperature because of the increasing entropy of the systems based on the equation $(\partial G / \partial T)_{\mathrm{V}}=-S$. From 0 to $1000 \mathrm{~K}$, the $\eta^{\prime}$ phase exhibits a lower free energy than the GPII zone, indicating that the $\eta^{\prime}$ phase is more stable than the GPII zone. Thus, the GPII zone can transform into the $\eta^{\prime}$ phase over the whole temperature range. With the increase in temperature, the free energy difference between the GP zone and the $\eta^{\prime}$ phase increases; consequently, the phase transformation rate of the GP zone to the $\eta^{\prime}$ phase should be enhanced by the traditional aging process.
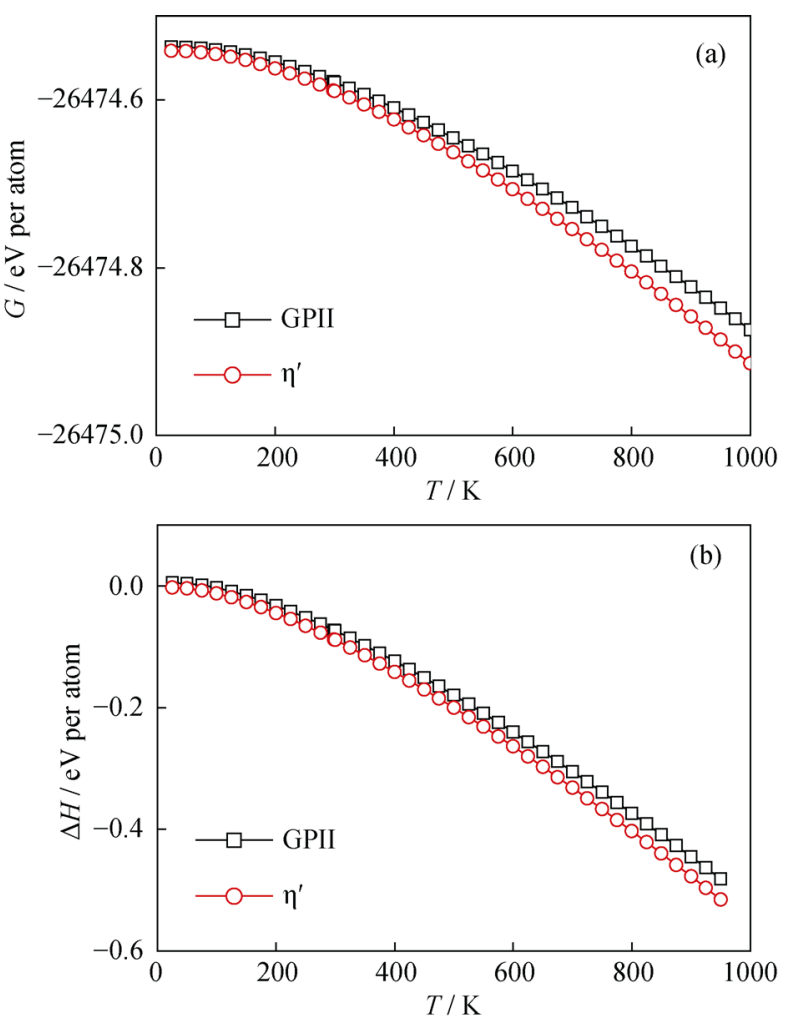

Fig. 6. Gibbs free energy (a) and the formation enthalpy (b) of the GPII zone and $\eta$ ' phase from 0 to $1000 \mathrm{~K}$.

When the aged $\mathrm{Al}$ alloys is subjected to a deep cryogenic treatment at $77 \mathrm{~K}$, the solid solubility and the permissible vacancy density are both decreased. Thus, the $\mathrm{Al}$ matrix aged at $393 \mathrm{~K}\left(120^{\circ} \mathrm{C}\right)$ is a supersaturated solid solution at $77 \mathrm{~K}$ and the excess solute atoms should precipitate. At the 
same time, when the temperature approaches $0 \mathrm{~K}$, the energy difference between the GPII zone and metastable $\eta^{\prime}$ phase is close to zero. In the current experiments, when the aged $\mathrm{Al}$ alloy is subjected to a deep cryogenic treatment at $77 \mathrm{~K}$, the energy difference between the GPII zone and metastable $\eta^{\prime}$ phase is small (as shown in Fig. 6(a)); thus, the transition from the GPII zone to the $\eta^{\prime}$ phase is virtually nonexistent. In addition, at deep cryogenic temperatures, the volume of the $\mathrm{Al}$ matrix will contract by $\sim 1 \%$ ( $V_{\mathrm{T}}=$ $V_{0} \mathrm{e}^{\alpha\left(T-T_{0}\right)}$, where $\alpha$ is the expansion coefficient, $V$ is the volume, and $T$ is the temperature), and the strain energy stored in the $\mathrm{Al}$ matrix acts as the driving energy for the second precipitation of GPII zones.

The formation enthalpies per atom of the GPII zone and $\eta$ ' phase can be calculated by

$$
\Delta H=\frac{1}{n_{1}+n_{2}+n_{3}}\left[E_{\mathrm{t}}-n_{1} E_{\mathrm{s}}^{\mathrm{Al}}-n_{2} E_{\mathrm{s}}^{\mathrm{Zn}}-n_{3} E_{\mathrm{s}}^{\mathrm{Mg}}\right]
$$

where $E_{\mathrm{t}}$ is the total enthalpy of the system calculated by the first-principles method, $E_{\mathrm{s}}^{\mathrm{Mg}}, E_{\mathrm{s}}^{\mathrm{Zn}}$, and $E_{\mathrm{s}}^{\mathrm{Al}}$ are the energies per atoms of bulk $\mathrm{Mg}, \mathrm{Zn}$, and $\mathrm{Al}$, respectively. Here, $\mathrm{s}$ stands for the bulk system on solid state. As shown in Fig. 6(b), the trend of the calculated formation enthalpies is similar to the trend in Fig. 6(a). The formation enthalpy is defined as the energy released or absorbed during a reaction, which determines the ease or difficulty of the formation of an intermetallic phase. When the formation enthalpy is negative, a larger absolute value will facilitate the formation of an intermetallic phase. Therefore, at low temperatures, the phase transformation from the GPII zone to the $\eta^{\prime}$ phase may be delayed.

As a result, the appearance of GPII zones in sample 6, as shown in Figs. 4(e)-4(n), resulted from the second precipitation of GPII zones during DCT after the sample was aged.

\section{Conclusions}

The effects of DCT-induced phase transformations in the $\mathrm{Al}-\mathrm{Zn}-\mathrm{Mg}-\mathrm{Cu}$ alloy was investigated in this study. The application of DCT can refine the grain size of the as-extruded Al sample, which improves its properties. However, DCT performed on the as-quenched $\mathrm{Al}$ alloy resulted in little influence on the properties of the aged sample. DCT performed after an aging treatment induces the second precipitation of GP zones in the Al matrix while simultaneously maintaining the favorable discontinuous distribution along grain boundaries with $30-40-\mathrm{nm}$ precipitate-free zones, which improves the properties of the alloy. Furthermore, the second precipitation has been demonstrated by first-prin- ciples calculations. In summary, DCT can alter the mechanical properties of $\mathrm{Al}$ alloys by perfecting their microstructures.

\section{Acknowledgements}

This work was financially supported by the Fundamental Research Funds for Central Universities of China (No. XDJK2014C008), the National Natural Science Foundation of China (No. 51171156), and the Key Scientific and Technoogical Projects of Chongqing (Nos. CSTC2012GGYS5001 and CSTC2013JCYJYS5002).

\section{References}

[1] L.T. Mai Hoa, Structural properties and evaluation of crystal fraction by cryogenic heat capacity measurements of Fe-based nanocrystalline alloy, J. Alloys Compd., 420(2006), No. 1-2, p. 50.

[2] A. Bensely, A. Prabhakaran, D. Mohan Lal, and G. Nagarajan, Enhancing the wear resistance of case carburized steel (En 353) by cryogenic treatment, Cryogenics, 45(2005), No. 12, p. 747.

[3] J.D. Darwin, D. Mohan Lal, and G. Nagarajan, Optimization of cryogenic treatment to maximize the wear resistance of $18 \% \mathrm{Cr}$ martensitic stainless steel by Taguchi method, $J$. Mater. Process. Technol., 195(2008), No. 1-3, p. 241.

[4] A. Akhbarizadeh, K. Amini, and S. Javadpour, Effects of applying an external magnetic field during the deep cryogenic heat treatment on the corrosion resistance and wear behavior of 1.2080 tool steel, Mater. Des., 41(2012), p. 114.

[5] F. Farhani, K.S. Niaki, S.E. Vahdat, and A. Firozi, Study of effects of deep cryotreatment on mechanical properties of 1.2542 tool steel, Mater. Des., 42(2012), p. 279.

[6] A. Bensely, D. Senthilkumar, D.M. Lal, G. Nagarajan, and A. Rajadurai, Effect of cryogenic treatment on tensile behavior of case carburized steel-815M17, Mater. Charact., 58(2007), No. 5, p. 485.

[7] A.I. Tyshchenko, W. Theisen, A. Oppenkowski, S. Siebert, O.N. Razumov, A.P. Skoblik, V.A. Sirosh, Yu.N. Petrov, and V.G. Gavriljuk, Low-temperature martensitic transformation and deep cryogenic treatment of a tool steel, Mater. Sci. Eng. $A, 527(2010)$, No. 26, p. 7027.

[8] S.H. Li, N. Min, J.W. Li, X.C. Wu, C.H. Li, and L.L. Tang, Experimental verification of segregation of carbon and precipitation of carbides due to deep cryogenic treatment for tool steel by internal friction method, Mater. Sci. Eng. A, 575(2013), p. 51.

[9] P.N. Rao and R. Jayaganthan, Effects of warm rolling and ageing after cryogenic rolling on mechanical properties and microstructure of Al 6061 alloy, Mater. Des., 39(2012), p. 226. 
[10] V. Subramanya Sarma, J. Wang, W.W. Jian, A. Kauffmann, H. Conrad, J. Freudenberger, and Y.T. Zhu, Role of stacking fault energy in strengthening due to cryo-deformation of FCC metals, Mater. Sci. Eng. A, 527(2010), No. 29-30, p. 7624.

[11] V. Subramanya Sarma, W.W. Jian, J. Wang, H. Conrad, and Y.T. Zhu, Effect of rolling temperature on the evolution of defects and properties of an Al-Cu alloy, J. Mater. Sci., 45(2010), No. 17, p. 4846.

[12] K.E. Lulay, K. Khan, and D. Chaaya, The effect of cryogenic treatments on 7075 aluminum alloy, J. Mater. Eng. Perform., 11(2002), No. 5, p. 479.

[13] M.O.H. Amuda and S. Mridha, Comparative evaluation of grain refinement in AISI 430 FSS welds by elemental metal powder addition and cryogenic cooling, Mater. Des., 35(2012), p. 609.

[14] G.Z. Ma, D. Chen, Z.H. Chen, and W. Li, Effect of cryogenic treatment on microstructure and mechanical behaviors of the Cu-based bulk metallic glass matrix composite, J. Alloys Compd., 505(2010), No. 1, p. 319.

[15] S.K. Panigrahi and R. Jayaganthan, Development of ultrafine grained high strength age hardenable Al 7075 alloy by cryorolling, Mater. Des., 32(2011), No. 6, p. 3150.

[16] S.K. Panigrahi and R. Jayaganthan, Development of ultrafine-grained Al 6063 alloy by cryorolling with the optimized initial heat treatment conditions, Mater. Des., 32(2011), No. 4, p. 2172.

[17] P. Baldissera, Deep cryogenic treatment of AISI 302 stainless steel: Part I. Hardness and tensile properties, Mater. Des., 31(2010), No. 10, p. 4725.

[18] P. Baldissera and C. Delprete, Deep cryogenic treatment of AISI 302 stainless steel: Part II. Fatigue and corrosion, Mater. Des., 31(2010), No. 10, p. 4731.

[19] L.H. Su, C. Lu, L.Z. He, L.C. Zhang, P. Guagliardo, A.K. Tieu, S.N. Samarin, J.F. Williams, and H.J. Li, Study of vacancy-type defects by positron annihilation in ultrafine-grained aluminum severely deformed at room and cryogenic temperatures, Acta Mater., 60(2012), No. 10, p. 4218.

[20] K.M. Asl, A. Tari, and F. Khomamizadeh, Effect of deep cryogenic treatment on microstructure, creep and wear behaviors of AZ91 magnesium alloy, Mater. Sci. Eng. A, 523(2009), No. 1-2, p. 27.

[21] Y. Liu, S. Shao, C.S. Xu, X.J. Yang, and D.P. Lu, Enhancing wear resistance of $\mathrm{Mg}-\mathrm{Zn}-\mathrm{Gd}$ alloy by cryogenic treatment, Mater. Lett., 76(2012), p. 201.

[22] G.Z. Ma, D. Chen, Y. Jiang, and W. Li, Cryogenic treatment-induced martensitic transformation in $\mathrm{Cu}-\mathrm{Zr}-\mathrm{Al}$ bulk metallic glass composite, Intermetallics, 18(2010), No. 6, p. 1254.

[23] C.L. Zhang, P.D. Han, Z.X. Zhang, M.H. Dong, L.L. Zhang, X.Y. Gu, Y.Q. Yang, and B.S. Xu, T Transformation of the $\theta$-phase in $\mathrm{Mg}-\mathrm{Li}-\mathrm{Al}$ alloys: a density functional theory study, J. Mol. Model., 18(2012), No. 3, p. 1123.

[24] C.L. Zhang, P.D. Han, X. Yan, C. Wang, L.Q. Xia, and B.S.
$\mathrm{Xu}$, First-principles study of typical precipitates in creep resistant magnesium alloys, J. Phys. D, 42(2009), No. 12, art. No. 125403.

[25] C.L. Zhang, P.D. Han, J.M. Li, M. Chi, L.Y. Yan, Y.P. Liu, X.G. Liu, and B.S. Xu, First-principles study of the mechanical properties of $\mathrm{NiAl}$ microalloyed by $\mathrm{M}(\mathrm{Y}, \mathrm{Zr}, \mathrm{Nb}, \mathrm{Mo}, \mathrm{Tc}$, Ru, Rh, Pd, Ag, Cd), J. Phys. D, 41(2008), art. No. 095410.

[26] X.L. Hu, X. Liu, Z. Xu, J.C. Liang, and T.M. Wang, First-principles investigation of the effects of B impurities on the mechanical properties of NiAl intermetallics, Sci. China Phys. Mech. Astron., 54(2011), No. 5, p. 809.

[27] J.J. Zhang, Z. Chen, Y.X. Wang, and B. Liu, Gibbs free energy calculation of $\mathrm{Al}-\mathrm{Cu}-\mathrm{Li}$ alloy with the effect of electric field from electron level, J. Alloys Compd., 457(2008), No. 1, p. 526.

[28] Y. Mogulkoc, Y.O. Ciftci, K. Colakoglu, and E. Deligoz, The structural, electronic, elastic, vibration and thermodynamic properties of GdMg, Solid State Sci., 16(2013), p. 168.

[29] K. Stiller, P.J. Warren, V. Hansen, J. Angenete, and J. Gjønnes, Investigation of precipitation in an $\mathrm{Al}-\mathrm{Zn}-\mathrm{Mg}$ alloy after two-step aging treatment at 100 and $150^{\circ} \mathrm{C}$, Mater. Sci. Eng. A, 270(1999), No. 1, p. 55.

[30] L.K. Berg, J. Gjønnes, V. Hansen, X.Z. Li, M. Knutson-Wedel, G. Waterloo, D. Schryvers, and L.R. Wallenberg, GP-zones in $\mathrm{Al}-\mathrm{Zn}-\mathrm{Mg}$ alloys and their role in artificial aging, Acta Mater., 49(2001), No. 17, p. 3443.

[31] S. Zhirafar, A. Rezaeian, and M. Pugh, Effect of cryogenic treatment on the mechanical properties of 4340 steel, J. Mater. Process. Technol., 186(2007), No. 1-3, p. 298.

[32] X.Z. Li, L. Hansen, J. GjØnnes, and L.R. Wallenberg, HREM study and structure modeling of the $\eta^{\prime}$ phase, the hardening precipitates in commercial $\mathrm{Al}-\mathrm{Zn}-\mathrm{Mg}$ alloys, Acta Mater., 47(1999), No. 9, p. 2651.

[33] A. Kverneland, V. Hansen, R. Vincent, K. Gjønnes, and J. Gjønnes, Structure analysis of embedded nano-sized particles by precession electron diffraction. $\eta^{\prime}$-precipitate in an $\mathrm{Al}-\mathrm{Zn}-\mathrm{Mg}$ alloy as example, Ultramicroscopy, 106(2006), No. 6, p. 492.

[34] T. Engdahl, V. Hansen, P.J. Warren, and K. Stiller, Investigation of fine scale precipitates in $\mathrm{Al}-\mathrm{Zn}-\mathrm{Mg}$ alloys after various heat treatments, Mater. Sci. Eng. A, 327(2002), No. 1, p. 59.

[35] J.C. Werenskiold, A. Deschamps, and Y. Bréchet, Characterization and modeling of precipitation kinetics in an Al-Zn-Mg alloy, Mater. Sci. Eng. A, 293(2000), No. 1-2, p. 267.

[36] J.Z. Chen, L. Zhen, S.J. Yang, W.Z. Shao, and S.L. Dai, Investigation of precipitation behavior and related hardening in AA 7055 aluminum alloy, Mater. Sci. Eng. A, 500(2009), No. $1-2$, p. 34.

[37] G. Sha and A. Cerezo, Early-stage precipitation in Al-Zn-Mg-Cu alloy (7050), Acta Mater., 52(2004), No. 15, p. 4503 . 